\title{
The Study on the Problems and Solutions of Training Engineering Talent in the Process of New-type Industrialization in China
}

\author{
Weifang Li \\ School of Management, Wuhan University of Science and Technology, Wuhan, 430081, China \\ wustlwf @163.com
}

Keywords: New-type Industrialization; Higher Engineering Education; Engineering Talent; Curriculum; Engineering Practice

\begin{abstract}
Taking the road of new-type industrialization is the difficult and necessary way to modernity in China. The higher engineering education in China should meet the requirement of the road of new-type industrialization. But the higher engineering education in China at present could't keep up with the socio-economic development, there are still some problems which are unlikely to adapt to the cultivation of advanced engineering talents. For instance, location unknown, unreasonable curriculum structure, lagging curriculum content and so on. For new-type industrialization, we should put forward countermeasures direct against these questions in higher engineering education, in order to further reform and improve the culture system of the higher engineering education in China.
\end{abstract}

\section{Introduction}

Taking the road of new-type industrialization is the precise location of the current development of our economy, at the same time it is the difficult and necessary way to modernity in China, which will significantly improve the global economy, the comprehensive national strength and people's living standard in China. [1]To a large extent, this depends on engineering technology and engineering management to push forward, so taking the road of new-type industrialization needs a great team of high-level engineering talents.

Higher engineering education in China is shouldering the heavy responsibility of cultivatng practical and complex cable engineering talents for economic construction. But the higher engineering education in China at present could't keep up with the socio-economic development, there are still some problems which are unlikely to adapt to the cultivation of advanced engineering talents for the new-type industrialization.[2] Reforming and improving unsuitable part in the talents cultivation in order to meet the demands of the new-type industrialization, which are urgent issues in the higher engineering education in China.

The Problems Existing in the Training Engineering Talent in the Process of New-type Industrialization in China

Location Unknown, No Strong Features, Unclear Level in the Higher Engineering Education in China. location unknown,not strong features, Unclear level in the higher engineering education in China. For some time, some comprehensive and specializes university are formed, the top universities are so desperately need. But some university blindly pursue scale and level, not focuse on quality and features. Firstly, some higher vocational and technical colleges weaken the features, trained personnels are lack of competitiveness, this has led to a severe skills shortage, vocational and technical education must undertake its function. Secondly, about undergraduate and graduate education, location unknown unclear Level, the tendency to pursue higher level are still in some universities. In recent years, the similar problems and unilaterally emphasizing general education in our colleges and universities, 
which cause that the students fostered focuse on basic theory and deliver the technology, specia education in undergraduate level are not been given enough attention.[3]

Unreasonable Curriculum Structure. Unreasonable curriculum structure. The problem of unreasonable curriculum structure about the highe engineering education in China reflects engineering practitioners, engineers generally have stronger and single technical skills, but are lack of wide knowledge, most experts possess one trait about too specialized rather than extensive. In big disciplines respect, most experts have only engineering technique knowledge, have not fundamental knowledge about management, economics and finance,etc. Even in the range of engineering technology, some experts master a narrow field of knowledge, but are lack of other technology knowledge associated with whole projects. Some engineering talents are good at doing experiments, researching data and writing thesis, but are not good at communicating with human and dealing with the outside world. These problems would be some severe restrictions of the future development for these engineering talents. Although these engineering talents can complete engineering task, they have great disparity with creating new technologies and high quality project. New-type industrialization and modernization greatly depend on engineering innovation education. With quick progress of the industrialization of China, engineering talents by cultivating of higher engineering education should have strong comprehensive ability, moving closer compound, forward-looking and innovative goal. So our higher engineering education should reform the existing curriculum structure, cultivating high-quality talents to adapt to the need of new-type industrialization.

Curriculum Content Has Lagged Behind Development of the New-type Industrialization. Curriculum content is an effective carrier. In the era of knowledge economy, which possesses the characteristics of digital, information and internalization, the contradiction between the speed of the replacement of the knowledge and the lagging of talent cultivation has become clear more and more. With the development of new-type industrialization, the latest technology in engineering domain has been changing with each passing day, curriculum content of the higher engineering education could't keep up with the pace of new-type industrialization. Curriculum content cannot reflect the latest knowledge and scientific research in engineering domain, especially some hot spot and main emphasises in some professional fields, with little reference to research and development of marginal discipline and high-new technology. Many old curriculum content havenot timely updated or eliminated. [4]

Less Practical Teaching in Higher Engineering Education in China. Via surveys, less practical teaching has been a common yet significant problem. Generally speaking, before receiving professional education, the students are lack of certain perceptual knowledge to engineering practice, are lack of fundamental and global concept of engineering practices problems which need to be solved. Because of paying much attention to impart theoretical knowledge, less practical teaching, the students are lack of truly experience about practical problems. These problems hamper the development of students' capability on solving practical problems by use of theoretical knowledge. That led to the experience of students is very poor, the students are difficult to meet the needs of engineering practices. Graduates are often lack of the ability of putting forward theoretical problem from engineering practice, and often lack of the ability of guiding engineering practice with the theory.

\section{Improving Countermeasure of Cultivating Engineering Talent}

The Goal and Orientation of Cultivating Engineering Talent Should Be Ambiguous. Countries all ower the world, especially the developed countries vigorously push to reform and development of engineering education, work hard to cultivate more excellent engineering talents, to stay ahead. In order to meet the demand of economy development. The goal of engineering talent training has the following characteristics: Turn past insistence on what to teach to now focus on what to study. Turn the "school-centered" education system to "students-centered". They emphasize that knowledge and 
ability of engineering graduates should meet the needs of economic and social development. Cultivation objects of engineering undergraduate students involve three aspects such as knowledge, capability and quality. It emphasizes project practice training and the training of many kinds of ability.[5] It emphasizes the combination of natura science and humanities, the close integration of engineering technique with economical management. Professional certification of engineering disciplines are directly tied to certified engineer's qualification, which identifies goal orientation of engineering education. Published in 2007, professional accreditation standards of engineering education in China, referring to standards of ABET, proposes 8 basic criterions about training objective of engineering undergraduate students, involving three aspects such as knowledge, capability and quality. Using foreign experience for reference, our engineering education should meet the needs of new-type industrialization.

Our Higher Engineering Education Should Be Hierarchical, Multi-stage and Multi-mode Teaching. From the whole education system, engineering education should further strengthen features of distinct levels and classified guidance. First, vocational and technical education should be paid more attention. The demanded quantity of skilled talent are great numbers in China, vocational and technical education should take its function. Second, the training of undergraduate and graduate students should definitude cultivation goal and teaching levels. We should emphasize hierarchical, multi-mode and less homogenous teaching. Various types of engineering education should be in their place, perform their respective duties, can't be blind to follow and compete. Training programs of engineering education should adjust itself to changes with relationship of mutual interdependence of university and engineering community in order to satisfy the demand of the changing market. Advanced technology talents for new-type industrialization should understand professional theory, be committed to technological innovation, have information and software tricks. Such talents training depend on comprehensive research university. These universities have rich specialty base, scientific spirit and humanit spirit, special education and general education develop simultaneously in these universities.

Optimizing Curriculum Structure, Building Wide-range and Multi-subjects Amalgamation Course System. For curriculum structure, first, the share of synthesized courses should be emphasised. By considering the characters of engineering practice and resulting problems, the interdisciplinary boundary should be broken, cross-discipline modules should be established. Second, the proportion of practical courses should be emphasized. [6]In developed country engineering specialties course, the proportion of practice is about a third of the deposits, each semester has almost practical courses. So, practical courses should be increased in our engineering majors curriculum. Meanwhile we should turn corresponding problems encountered in engineering practices to some correlative questions in scientific research, through the opening of practical courses, in order to increase the scientific research ability of engineering talents. Third, curriculum structure should emphasize meeting the student personalization need of develop. [7]The course system of engineering specialty is too stereotypical for a long time, ignoring students' personality, cannot arouse the students enthusiasm effectively. Fourth, for engineering talents having broad professional perspective, cross-disciplinary courses should be offered more, we should expand the degree of freedom of the students' course selection. Fifth, for training students' innovative power, about curriculum structure, the professional learning contents should become special education from general education Gradually, with progressive learning content. All courses should serve for engineering profession, in order to set up capacity indicator system of engineering talents, focus on natural sciences and humanities social sciences, focus on the integration of technique with management. order to set up. According to these indicator system, redesign

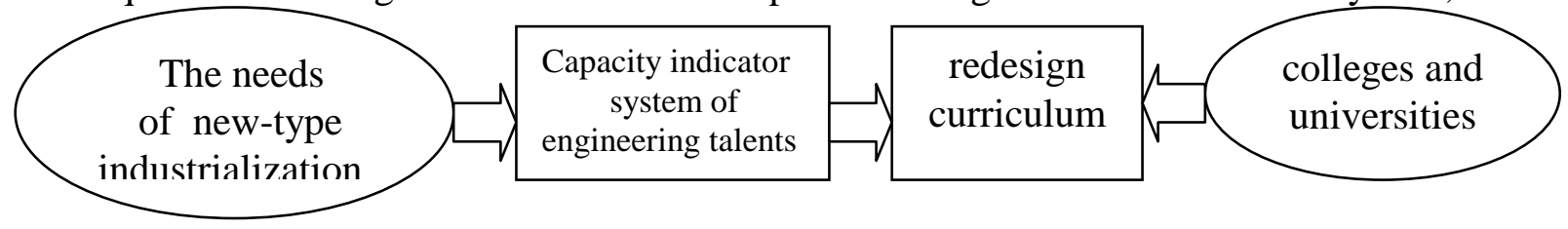

Fig. 1 The Relationship of the new-type industrialization and curriculum design 
curriculum. As shown in Fig. 1

Through Cooperation of Production, Study and Research, Strengthen Engineering Practice Training. The core of engineering education is practice ability training, the capability of solving the practical engineering problems is fundamental ability of engineering talent.[8] In order to train profound theoretical foundation and abundant experience engineering talent, cultivating the practice ability should flow through all teaching links. To ensure practice link producing the expected effect, some courses should engage entrepreneurship specialist as main speaker teacher, graduation design should encourage the system of Two-Tutor, be supervised by school and enterprise mentor.[9] For the practice base, university should rely on cooperation of more relevant units.

Continuous Reform in Teaching Content and Teaching Method. Higher education combines knowledge with skills at much higher levels. So teaching content should be continuous reformed for the requirement of engineering practice, emphasis on practicality. The changes of engineering technology are high-speed and complexity, these call for that teaching content of training engineering talent should fully embody the advanced knowledge, recent developments and latest achievement of engineering domain[10]. In addition, the reform of teaching methods should be paid attention. We should strengthen heuristic teaching, case-teaching and student's independent learning. The teachers should introduce more ideas, methods, lates cases and academic developments, emphasis on training the student's learning way and develop the student's learning abilities, inspire the student's creativity.

\section{Conclusions}

The growth of engineering talents is continuous, system. In order to cultivate creative talents with high levels to meet the needs of new-type industrialization in China, we should study the problem and countermeasures of the higher engineering education in China at present with deeper thinking.

\section{Acknowledgements}

This work was financially supported by Hubei Province Education and Science, "Twelfth Five-Year Plan" Annua Issue in 2014 "the research on the engineering talent cultivating pattern innovation of the process of the new-type industrialization" (No:2014A018)

\section{References}

[1] Information on http://rencai.people.com, 2015.3.20.

[2] Wang Yingjun, With the Demand of National New Industrialization, Cultivate Engineering Innovative Talents, Higher Education in China, 2012(6): 12-13

[3] Wu Xhaofen, The New Mission of Higher Engineering Education in the New Industrialization Path, Higher Education in China, 2004(18): 6-8

[4] $\mathrm{Hu}$ Fengchi, Problems and Countermeasures of Engineering Master's Training Under the Background of the New-industrialization, China Electric Power Education, 2009(10): 64-65.

[5] Gao Wenbing,huangboyun, For New-type Industrialization, Train Advanced Technology Undergraduate Talents, Higher Education in China,2009(10):7-9.

[6] Xu Xiangmin, For New-type Industrialization, Cultivate High-quality Innovative Talents, Higher Engineering Education Research, 2012(4):15-24.

[7] Yan Ling, The Professional Programmatic Accreditation System and Acting Mechanisms of Application-oriented Undergraduate, Tsinghua Journal of Education, 2012(4) 
[8] Zhang Lishan, The Professional Ability Cultivation of Engineering Management Professional Students, Education and Career, 2013(26)

[9] Information on http:// theory.people.com.cn/n/2012.10

[10] Yang Qiubo, The Exploration of Project Management Specialty Practice Educational System, Journal of Tianjin University( Social Sciences), 2013(6). 